\title{
Lipocalin-1 Expression as a Prognosticator Marker of Survival in Breast Cancer Patients
}

\author{
Xueyan Zhang ${ }^{a}$ Yingnan Cui $^{b}$ Miao He ${ }^{c}$ Yan Jiao $^{d}$ Zhaoying Yang ${ }^{b}$ \\ aSchool of Nursing, Jilin University, Changchun, China; \\ ${ }^{b}$ Department of Breast Surgery, China-Japan Union Hospital of Jilin University, Changchun, China; \\ 'Department of Anesthesia, The Second Hospital of Jilin University, Changchun, China; \\ ${ }^{\mathrm{d}}$ Department of Hepatobiliary and Pancreatic Surgery, The First Hospital of Jilin University, Changchun, China
}

\section{Keywords}

Breast cancer · Diagnosis · LCN1 · Lipocalin-1 · Prognosis · Tear lipocalin

\begin{abstract}
Purpose: LCN1 (lipocalin-1), a gene that encodes tear lipocalin (or von Ebner's gland protein), is mainly expressed in secretory glands and tissues, such as the lachrymal and lingual gland, and nasal, mammary, and tracheobronchial mucosae. Analysis of the Cancer Genome Atlas (TCGA) Breast Carcinoma (BRCA) level 3 data revealed a relationship between LCN1 expression and survival in breast cancer patients. Methods: The $X^{2}$ test and Fisher exact test were applied to analyze the clinical data and RNA sequencing expression data, and the association between LCN1 expression and clinicopathologic features was determined. The receiver-operating characteristic (ROC) curve of LCN1 was drawn to assess its ability as a diagnostic marker, and the optimal cutoff value was obtained from the ROC curve to distinguish groups with high and low LCN1 expression. Cox regression was used to compare both groups, and a log-rank test was applied to calculate $p$ values and compare the Kaplan-Meier curves. Furthermore, GEO datasets were employed for external data validation. Results: Analysis of 1,104 breast cancer patients with a primary tumor revealed that LCN1 was overexpressed in breast cancer. High LCN1 expres-
\end{abstract}

Y.J. and Z.Y. contributed equally to this work and should be regarded as co-corresponding authors.

karger@karger.com

www.karger.com/brc

Karger'
() 2019 The Author(s)

Published by S. Karger AG, Basel

Karger

Open access

This article is licensed under the Creative Commons AttributionNonCommercial-NoDerivatives 4.0 International License (CC BYNC-ND) (http://wwwkarger.com/Services/OpenAccessLicense). Usage and distribution for commercial purposes as well as anse). Usage and distribution for commercial purposes as well as any dis sion was associated with clinicopathologic features and poor survival. Analyzing the area under the ROC curve (AUC) of LCN1, it was found that its diagnostic ability was limited. Multivariate analysis indicated that LCN1 expression is an independent predictor of survival in breast cancer patients. Through validation in GEO datasets, LCN1 expression was higher in tumor than normal tissue of the breast. High LCN1 expression was associated with poor survival in breast cancer patients. Conclusions: High LCN1 expression is an independent prognosticator of a poor prognosis in breast cancer.

\section{(c) 2019 The Author(s)}

Published by S. Karger AG, Basel

\section{Introduction}

Breast cancer is the most common cancer worldwide and the leading cause of cancer death in women $[1,2]$. It can be divided into 5 molecular subtypes on the basis of its intrinsic molecular profiles, including luminal $\mathrm{A}, \mathrm{lu}-$ minal B, HER2-enriched, basal-like, and normal-like breast cancer. Currently, there are well-established prognostic and/or therapeutic breast cancer markers like ER (estrogen receptor), PR (progesterone receptor), HER2 (human epidermal growth factor receptor 2), Ki67 antigen, tumor protein p53, and breast cancer susceptibility genes (BRCA1 and BRCA2) [3]. Exosomal biomarkers (such as CD47, Del-1, miR-1246, and miR-21) can be ap- 
Table 1. Correlations of LCN1 expression in breast cancer tissue with clinicopathologic features

\begin{tabular}{|c|c|c|c|c|c|}
\hline \multirow[t]{2}{*}{ Clinical characteristics } & \multirow{2}{*}{$\begin{array}{l}\text { Cases, } \\
n\end{array}$} & \multicolumn{2}{|c|}{ LCN1 expression, $n(\%)$} & \multirow{2}{*}{$\begin{array}{l}\chi^{2} \\
\text { test }\end{array}$} & \multirow[t]{2}{*}{$p$ value } \\
\hline & & high & low & & \\
\hline \multicolumn{6}{|l|}{ Age } \\
\hline$<60$ years & $589(53.45)$ & $102(17.32)$ & $487(82.68)$ & \multirow[t]{2}{*}{0.0000} & \multirow[t]{2}{*}{1.0000} \\
\hline$\geq 60$ years & $513(46.55)$ & $88(17.15)$ & $425(82.85)$ & & \\
\hline \multicolumn{6}{|l|}{ Gender } \\
\hline Female & $1,090(98.73)$ & $188(17.25)$ & $902(82.75)$ & \multirow[t]{2}{*}{0.0000} & \multirow[t]{2}{*}{1.0000} \\
\hline Male & $12(1.09)$ & $2(16.67)$ & $10(83.33)$ & & \\
\hline \multicolumn{6}{|l|}{ Histological type } \\
\hline Infiltrating ductal carcinoma & $790(71.56)$ & $147(18.61)$ & $643(81.39)$ & \multirow[t]{3}{*}{5.3376} & \multirow[t]{3}{*}{0.0693} \\
\hline Infiltrating lobular carcinoma & $204(18.48)$ & $24(11.76)$ & $180(88.24)$ & & \\
\hline Other & $107(9.69)$ & $19(17.76)$ & $88(82.24)$ & & \\
\hline \multicolumn{6}{|l|}{ Molecular subtype } \\
\hline Basal & $142(12.86)$ & $29(20.42)$ & $113(79.58)$ & \multirow[t]{5}{*}{8.6955} & 0.0692 \\
\hline HER2 & $67(6.07)$ & $13(19.4)$ & $54(80.6)$ & & \\
\hline Luminal A & $422(38.22)$ & $58(13.74)$ & $364(86.26)$ & & \\
\hline Luminal B & $194(17.57)$ & $22(11.34)$ & $172(88.66)$ & & \\
\hline Normal & $24(2.17)$ & $6(25)$ & $18(75)$ & & \\
\hline ER & & & & & \\
\hline Indeterminate & $2(0.18)$ & $0(0)$ & $2(100)$ & 6.2464 & 0.0440 \\
\hline Negative & $239(21.65)$ & $54(22.59)$ & $185(77.41)$ & & \\
\hline Positive & $813(73.64)$ & $129(15.87)$ & $684(84.13)$ & & \\
\hline PR & & & & & \\
\hline Indeterminate & $4(0.36)$ & $0(0)$ & $4(100)$ & 5.7837 & 0.0555 \\
\hline Negative & $345(31.25)$ & $73(21.16)$ & $272(78.84)$ & & \\
\hline Positive & $704(63.77)$ & $110(15.63)$ & $594(84.38)$ & & \\
\hline HER2 & & & & & \\
\hline Equivocal & $180(16.3)$ & $31(17.22)$ & $149(82.78)$ & 0.9357 & 0.8168 \\
\hline Indeterminate & $12(1.09)$ & $2(16.67)$ & $10(83.33)$ & & \\
\hline Negative & $565(51.18)$ & $100(17.7)$ & $465(82.3)$ & & \\
\hline Positive & $164(14.86)$ & $34(20.73)$ & $130(79.27)$ & & \\
\hline Menopause status & & & & & \\
\hline Indeterminate & $34(3.08)$ & $3(8.82)$ & $31(91.18)$ & 16.3272 & 0.0010 \\
\hline Perimenopausal & $40(3.62)$ & $13(32.5)$ & $27(67.5)$ & & \\
\hline Postmenopausal & $706(63.95)$ & $134(18.98)$ & $572(81.02)$ & & \\
\hline Premenopausal & $231(20.92)$ & $25(10.82)$ & $206(89.18)$ & & \\
\hline T classification & & & & & \\
\hline $\mathrm{T} 1$ & $281(25.45)$ & $48(17.08)$ & $233(82.92)$ & 0.8468 & 0.9321 \\
\hline $\mathrm{T} 2$ & $640(57.97)$ & $110(17.19)$ & $530(82.81)$ & & \\
\hline $\mathrm{T} 3$ & $138(12.5)$ & $24(17.39)$ & $114(82.61)$ & & \\
\hline $\mathrm{T} 4$ & $40(3.62)$ & $8(20)$ & $32(80)$ & & \\
\hline $\mathrm{Tx}$ & $3(0.27)$ & $0(0)$ & $3(100)$ & & \\
\hline $\mathrm{N}$ classification & & & & & \\
\hline N0 & $516(46.74)$ & $90(17.44)$ & $426(82.56)$ & 7.3576 & 0.1182 \\
\hline N1 & $367(33.24)$ & $56(15.26)$ & $311(84.74)$ & & \\
\hline N2 & $120(10.87)$ & $30(25)$ & $90(75)$ & & \\
\hline N3 & $79(7.16)$ & $10(12.66)$ & $69(87.34)$ & & \\
\hline $\mathrm{Nx}$ & $20(1.81)$ & $4(20)$ & $16(80)$ & & \\
\hline M classification & & & & & \\
\hline Mo & $917(83.06)$ & $152(16.58)$ & $765(83.42)$ & 2.4890 & 0.2881 \\
\hline M1 & $22(1.99)$ & $6(27.27)$ & $16(72.73)$ & & \\
\hline $\mathrm{Mx}$ & $163(14.76)$ & $32(19.63)$ & $131(80.37)$ & & \\
\hline Stage & & & & & \\
\hline I & $182(16.49)$ & $28(15.38)$ & $154(84.62)$ & 4.0374 & 0.4010 \\
\hline II & $626(56.7)$ & $108(17.25)$ & $518(82.75)$ & & \\
\hline III & $252(22.83)$ & $47(18.65)$ & $205(81.35)$ & & \\
\hline IV & $20(1.81)$ & $6(30)$ & $14(70)$ & & \\
\hline $\mathrm{X}$ & $14(1.27)$ & $1(7.14)$ & $13(92.86)$ & & \\
\hline Lymph node involvement & & & & & \\
\hline No & $28(2.54)$ & $4(14.29)$ & $24(85.71)$ & 0.0165 & 0.8977 \\
\hline Yes & $697(63.13)$ & $119(17.07)$ & $578(82.93)$ & & \\
\hline
\end{tabular}


Table 1 (continued)

\begin{tabular}{|c|c|c|c|c|c|}
\hline \multirow[t]{2}{*}{ Clinical characteristics } & \multirow{2}{*}{$\begin{array}{l}\text { Cases, } \\
n\end{array}$} & \multicolumn{2}{|c|}{ LCN1 expression, $n(\%)$} & \multirow{2}{*}{$\begin{array}{l}\chi^{2} \\
\text { test }\end{array}$} & \multirow[t]{2}{*}{$p$ value } \\
\hline & & high & low & & \\
\hline \multicolumn{6}{|l|}{ Margin status } \\
\hline Close & $31(2.81)$ & $9(29.03)$ & $22(70.97)$ & 3.1951 & 0.2024 \\
\hline Negative & $922(83.51)$ & $159(17.25)$ & $763(82.75)$ & & \\
\hline Positive & $79(7.16)$ & $12(15.19)$ & $67(84.81)$ & & \\
\hline \multicolumn{6}{|l|}{ Vital status } \\
\hline Deceased & $155(14.04)$ & $35(22.58)$ & $120(77.42)$ & 3.1814 & 0.0745 \\
\hline Living & $947(85.78)$ & $155(16.37)$ & $792(83.63)$ & & \\
\hline \multicolumn{6}{|l|}{ Radiation therapy } \\
\hline No & $445(40.31)$ & $84(18.88)$ & $361(81.12)$ & 0.7950 & 0.3726 \\
\hline Yes & $557(50.45)$ & $92(16.52)$ & $465(83.48)$ & & \\
\hline \multicolumn{6}{|l|}{ Neoadjuvant treatment } \\
\hline No & $1,088(98.55)$ & $188(17.28)$ & $900(82.72)$ & 0.0000 & 1.0000 \\
\hline Yes & $13(1.18)$ & $2(15.38)$ & $11(84.62)$ & & \\
\hline \multicolumn{6}{|c|}{ Targeted molecular therapy } \\
\hline No & $46(4.17)$ & $5(10.87)$ & $41(89.13)$ & 0.2960 & 0.5864 \\
\hline Yes & $533(48.28)$ & $80(15.01)$ & $453(84.99)$ & & \\
\hline \multicolumn{6}{|l|}{ Sample type } \\
\hline Metastatic & $7(0.63)$ & $0(0)$ & $7(100)$ & 0.5011 & 0.4790 \\
\hline Primary tumor & $1,097(99.37)$ & $190(17.32)$ & $907(82.68)$ & & \\
\hline
\end{tabular}

Bold values $(p<0.05)$ indicate statistically significant correlations. High and low LCN expression added up to $100 \%$ in each subgroup, e.g., age <60 years: high LCN1 expression $17.32 \%(102 / 589)+$ low LCN1 expression $82.68 \%(487 / 589)=100 \%(589)$.

plied for the early diagnosis and prognosis of breast cancer [2]. Gene biomarkers also showed a certain degree of prognostic value in breast cancer, including uPA, PAI-1, cyclin D, cyclin E, p27, and p21 [4]. More effective prognostic factors for breast cancer will be discovered with the development of biological science and technology.

LCN1 (lipocalin-1), known as tear lipocalin, is the main lipid-binding protein in tears. It can be combined with a variety of hydrophobic molecules, including fatty acids, fatty alcohols, retinoic acid, retinol, cholesterol, phospholipids, glycolipids, and arachidonic acid and its peroxidation products [5]. LCN1 is a member of the lipocalin family, which has the ability to scavenge hydrophobic, potentially harmful molecules [6] and was associated with several diseases, including primary open angle glaucoma [7], keratoconus tears [8], and meibomian gland disease [9]. It was identified in a number of tissues and glands, including mammary, nasal, and testicular mucosae [10], the lachrymal, lingual, and sweat gland, the mucosal gland of the tracheobronchial tree [11], and the prostate [12]. Another member of the lipocalin superfamily, LCN2 (lipocalin-2), plays an important role in the progression of cancer [13]. It was reported to promote breast cancer progression and was highly associated with ER-negative breast tumors [14]. However, the relationship between LCN1 and breast cancer is still unknown. Therefore, we explored this relationship in an innovative way to make up for the gap of LCN1 in breast cancer.
The relationship between LCN1 expression and the prognosis of survival was investigated in breast cancer patients through analysis of the Cancer Genome Atlas (TCGA) breast cancer (BRCA) level 3 data. GEO datasets were used for external data validation. To our knowledge, this is the first time LCN1 has been linked to breast cancer.

\section{Materials and Methods}

\section{Data Mining}

The clinical data and RNA sequencing expression data of breast cancer patients were downloaded from TCGA (https://cancergenome.nih.gov/). We applied RNA sequencing by expectationmaximization expression values to the analysis process. GEO datasets were downloaded from the GEO database (https://www. ncbi.nlm.nih.gov/geo/).

\section{Statistical Analysis}

Using the ggplot2 package in $\mathrm{R}$, the expression difference of discrete variables was visualized into boxplots. The $\chi^{2}$ test and the Fisher exact test were used to find the correlation between LCN1 expression and clinicopathologic features in $\mathrm{R}$ (version 3.5.2). To assess the diagnostic capability of LCN1, the pROC package was applied to draw its ROC curve, and the optimal cutoff value was obtained from the ROC curve to determine high and low LCN1 expression groups. Through the survival package of R, we used the Kaplan-Meier curves to compare differences in overall survival and relapse-free survival between both groups. $p$ values were calculated by log-rank test. Univariate analysis was applied to screen significant clinicopathologic features, and multivariate analysis confirmed that LCN1 expression affected the survival of breast cancer patients. 


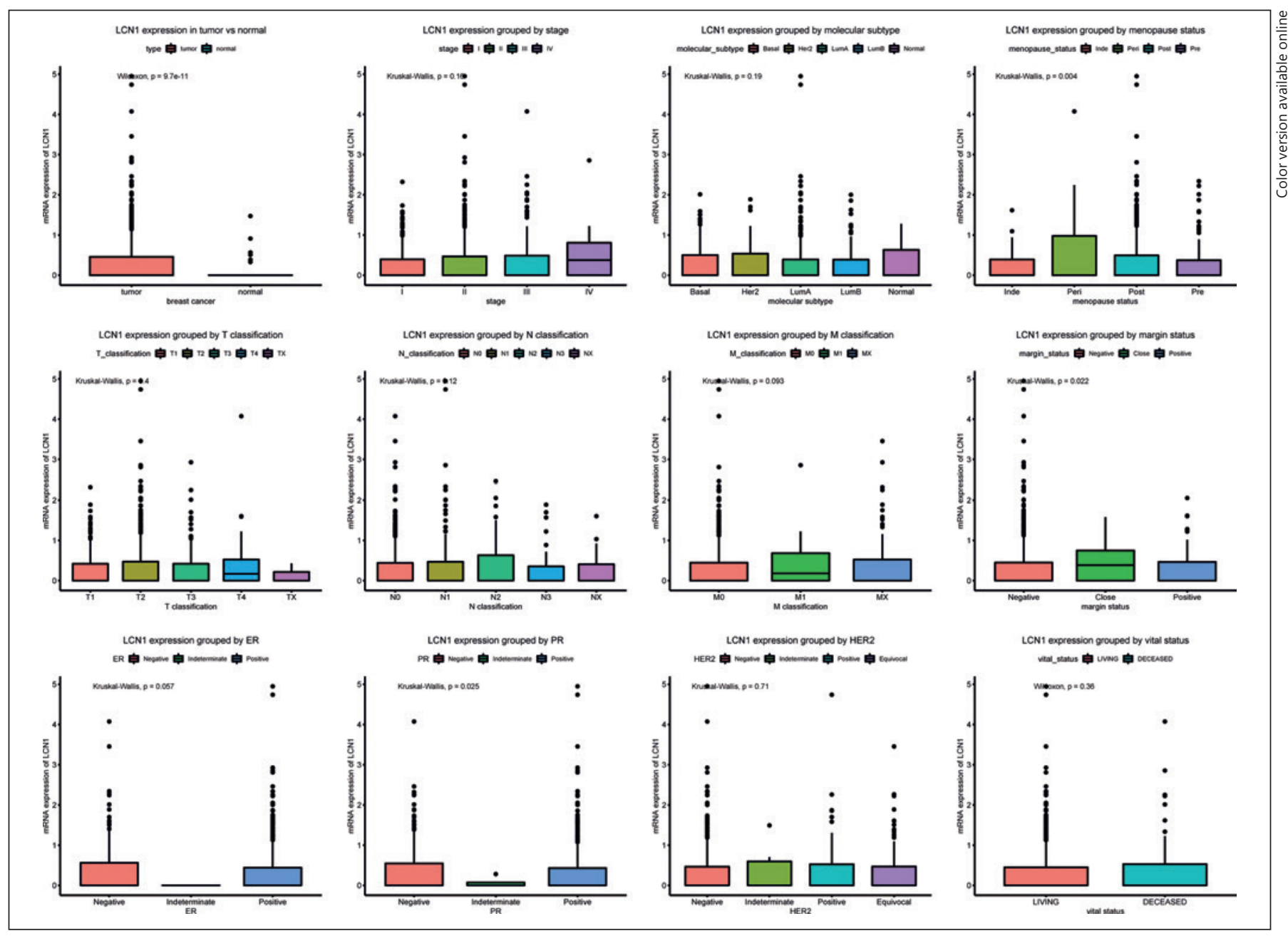

Fig. 1. Differences in LCN1 expression were shown in boxplots according to clinical stage, molecular subtype, menopause status, TNM stage, tumor margins, and ER, PR, HER2, and vital status.

\section{Results}

\section{Patient Characteristics}

We analyzed the TCGA-BRCA level 3 data. The clinical characteristics included age, gender, menopause status, ER, PR, HER2, TNM stage, clinical stage, histological type, molecular subtype, lymph node status, margin status, vital status, neoadjuvant treatment, radiation therapy, targeted molecular therapy, and sample type. The corresponding patient characteristics are listed in Table 1.

\section{LCN1 Expression and Association with \\ Clinicopathologic Features in Breast Cancer}

LCN1 expression was higher in tumor than in normal tissue $(p=9.7 \mathrm{e}-11)$. Moreover, differences in LCN1 expression were shown in boxplots according to clinical stage, molecular subtype, menopause status $(p=0.004)$, TNM stage, margin status $(p=0.022)$, ER, PR $(p=0.025)$, HER2, and vital status (Fig. 1). Then we validated it in
GEO datasets. LCN1 expression was also higher in breast tumor than in normal breast tissue in GSE5764, GSE40057, and GSE26910 (online suppl. Fig. S1; see www.karger.com/doi/10.1159/000503168 for all online suppl. material). The $\chi^{2}$ and Fisher exact test were used. The results revealed that high LCN1 expression was associated with $\operatorname{ER}(p=0.0440)$ and menopause status ( $p=$ 0.0010; Table 1). Besides, the results of LCN1 validation in GEO datasets also showed that breast tissue had a higher LCN1 expression than adipose fat in women at increased risk of breast cancer $(p=3 e-15)$ based on GSE66159 (online suppl. Fig. S2A). We compared LCN1 expression in patients with primary breast tumor in different body mass index (BMI) groups $(p=0.0088)$ : normal (BMI $\leq 24.9$ ), overweight (BMI 25-29.9), and obese patients (BMI $\geq 30)$. LCN1 expression was significantly higher in the obese group than in the normal group (online suppl. Fig. S2B) and was positively correlated with BMI $\left(R^{2}=0.0429\right)$ based on GSE24185 (online suppl. Fig. S2C). 


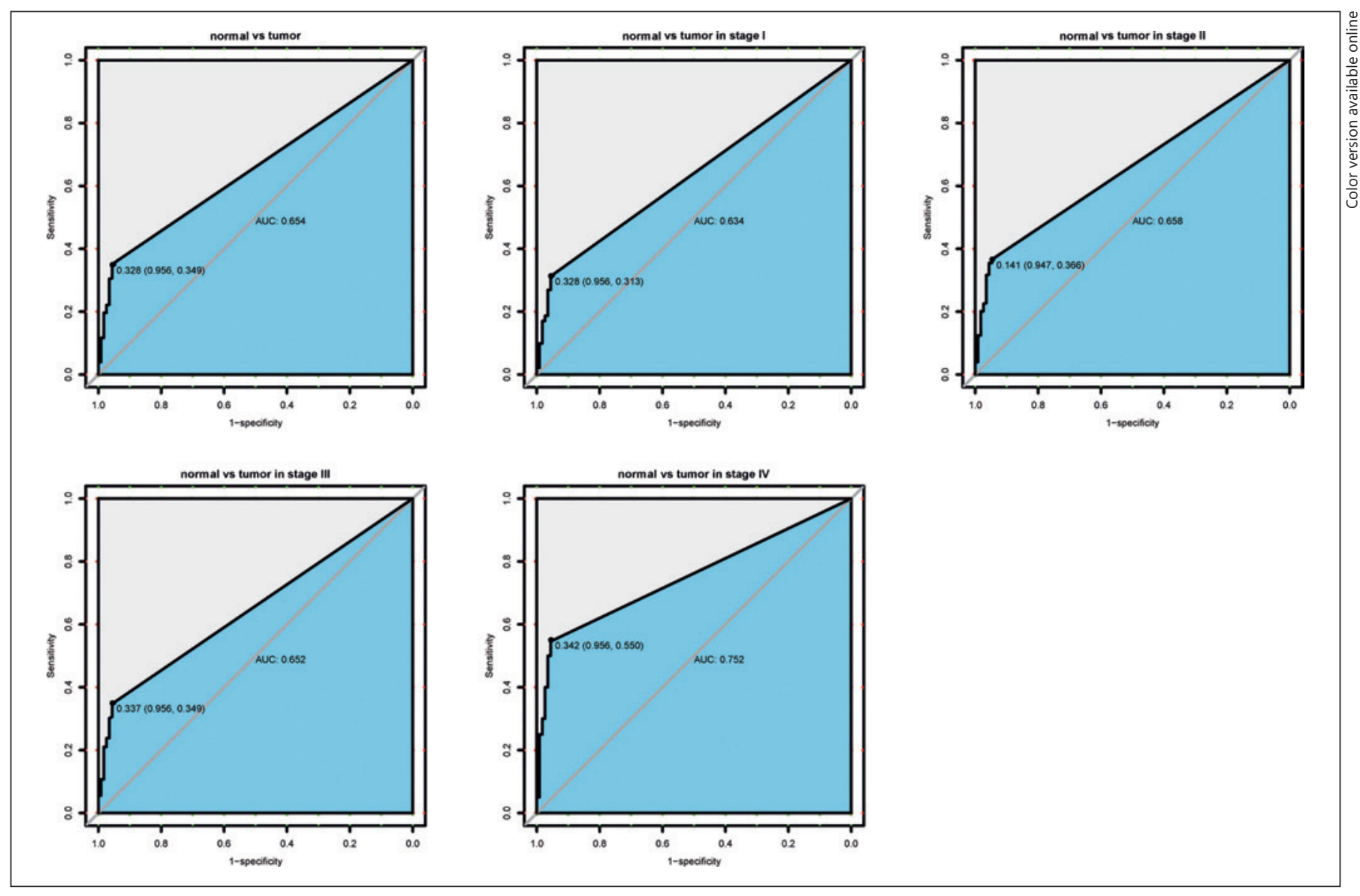

Fig. 2. The receiver-operating characteristic curve of LCN1 in different clinical stages (normal vs. tumor). AUC, area under the curve.

\section{Diagnostic Capability of LCN1 Expression}

The AUC in the ROC curve of LCN1 was 0.654 , which indicated its limited diagnostic capability. Subgroup analyses of the different stages were also shown. It revealed moderate diagnostic capability in stage IV (AUC: stage I, 0.634; stage II, 0.658; stage III, 0.652; stage IV, 0.752; Fig. 2).

\section{LCN1 Expression and Breast Cancer Survival}

The Kaplan-Meier curves were used to determine the relationship between LCN1 expression and breast cancer survival. Using log-rank tests, high LCN1 expression was associated with poor overall survival ( $p=0.00015$; Fig. 3 ) and poor relapse-free survival ( $p=0.0044$; Fig. 4). Subgroup analyses revealed that high LCN1 expression was correlated with poor overall survival in patients with ERnegative $(p=0.0020)$ and HER2-negative $(p=0.0099)$ tumors, PR tumors (negative: $p=0.0071$; positive: $p=$ $0.0400)$, and infiltrating ductal carcinoma $(p=0.0062$; Fig. 3). The analyses also revealed that high LCN1 expression was related to poor relapse-free survival in patients with ER-negative tumors $(p=0.0370)$, HER2 tumors (negative: $p=0.0300$; positive: $p=0.0200$ ), luminal B tu- mors $(p=0.0100)$, and infiltrating ductal carcinoma ( $p=$ 0.0460; Fig. 4). The prognostic role of LCN1 was validated in GEO datasets (GSE20711, GSE42568, and GSE88770), and the Kaplan-Meier curves showed that high LCN1 expression was associated with poor overall survival and poor relapse-free survival (online suppl. Fig. S3).

\section{High LCN1 Expression as an Independent Predictor for Poor Survival in Breast Cancer}

Univariate analysis was applied to screen significant clinicopathologic features, and multivariate analysis confirmed that LCN1 expression affected the survival of breast cancer patients. Univariate analysis showed that poor overall survival was related to age, HER2, clinical stage, margin status, and LCN1 expression (Table 2). Similarly, poor relapse-free survival was related to ER, PR, clinical stage, margin status, and LCN1 expression (Table 3). Multivariate analyses indicated that high LCN1 expression was an independent predictor of poor overall survival $(p=0.002$; HR 2.24, 95\% CI 1.33-3.78; Table 2) and poor relapsefree survival ( $p=0.016$; HR 1.85, 95\% CI 1.12-3.06; Table 3). 


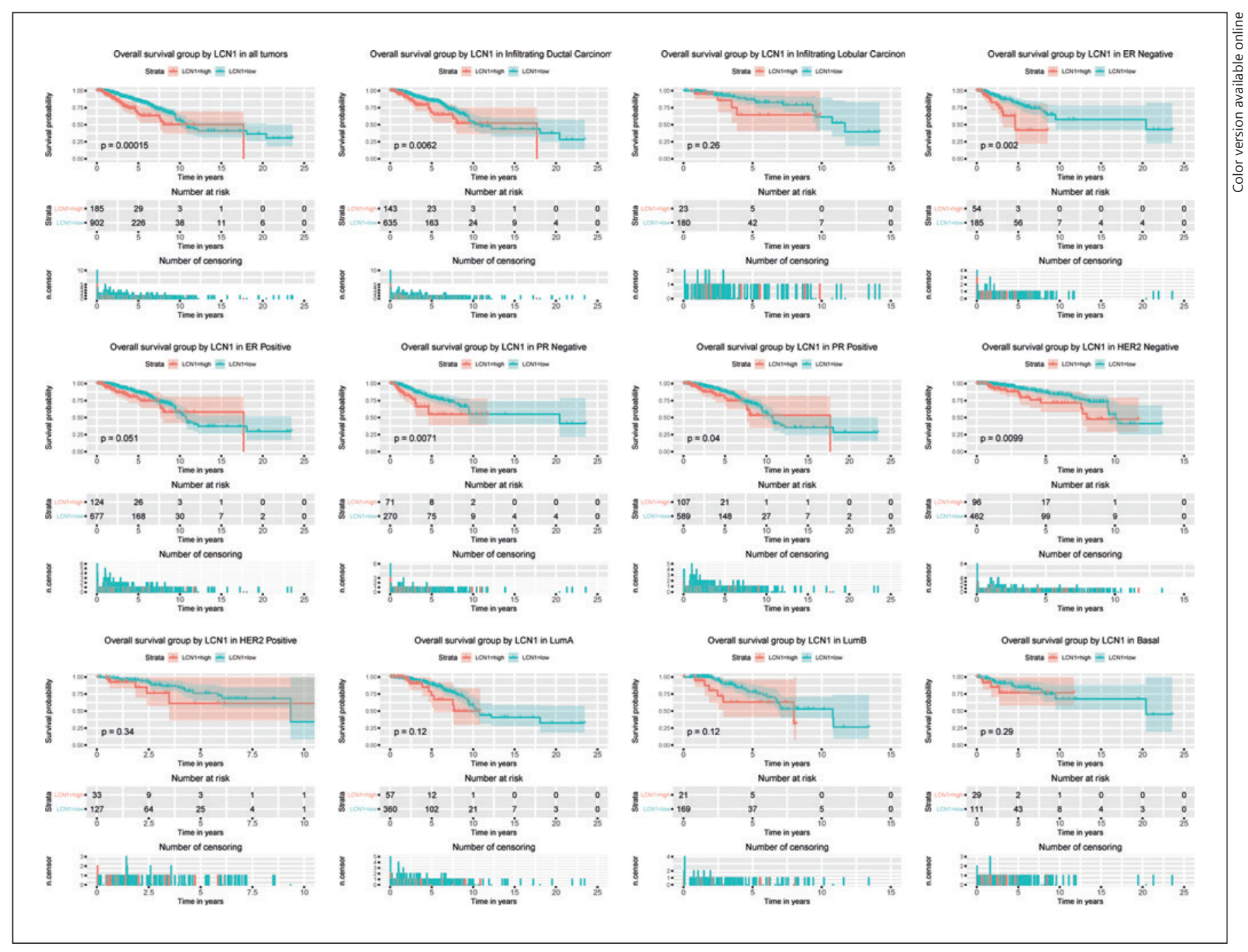

Fig. 3. Kaplan-Meier curves of overall survival in breast cancer. Overall survival analysis and subgroup analyses of histological type, ER, PR, HER2, and molecular subtype.

Table 2. Univariate and multivariate analyses of overall survival in breast cancer patients

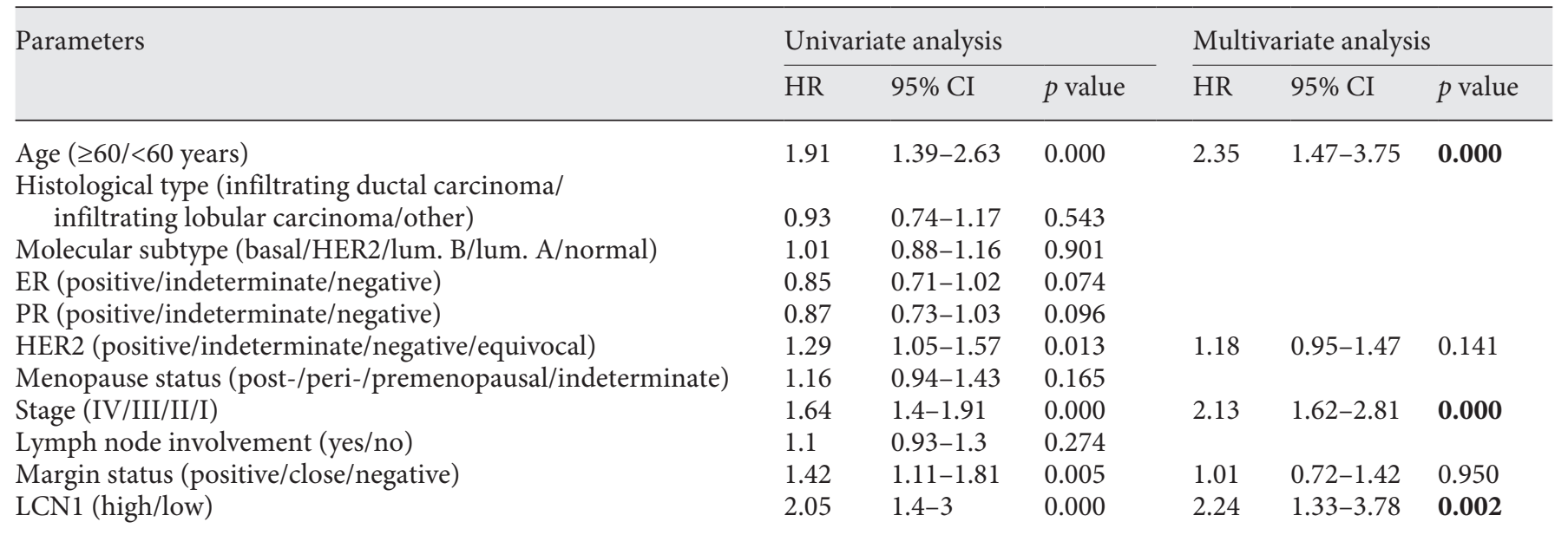

Bold values $(p<0.05)$ indicate statistically significant correlations. HR, hazard ratio; CI, confidence interval, lum., luminal. 


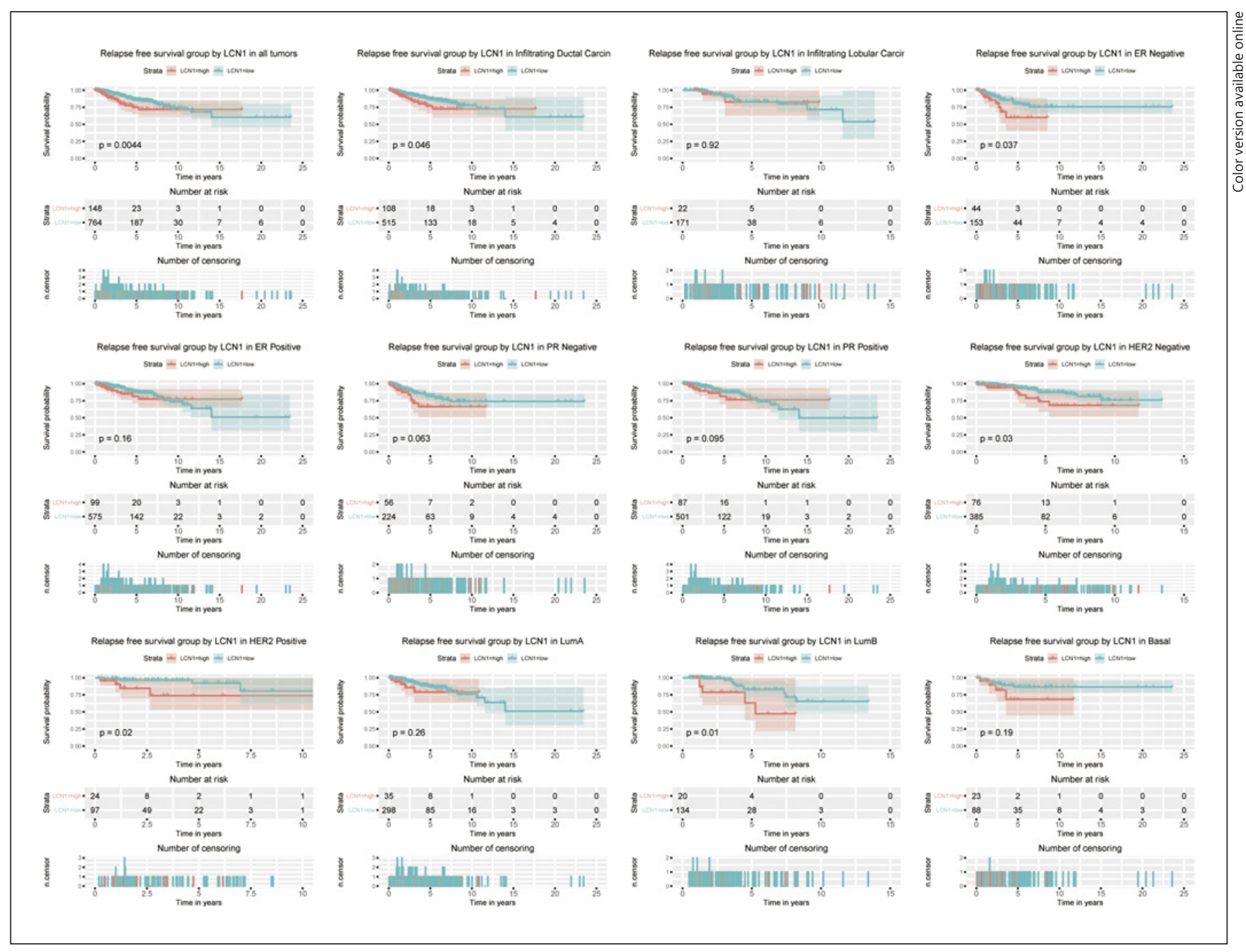

Fig. 4. Kaplan-Meier curves of relapse-free survival in breast cancer. Relapse-free survival analysis and subgroup analyses of histological type, ER, PR, HER2, and molecular subtype.

Table 3. Univariate and multivariate analyses of relapse-free survival in breast cancer patients

\begin{tabular}{|c|c|c|c|c|c|c|}
\hline \multirow[t]{2}{*}{ Parameters } & \multicolumn{3}{|c|}{ Univariate analysis } & \multicolumn{3}{|c|}{ Multivariate analysis } \\
\hline & HR & $95 \% \mathrm{CI}$ & $p$ value & HR & $95 \% \mathrm{CI}$ & $p$ value \\
\hline Age $(\geq 60 /<60$ years $)$ & 1.45 & $0.97-2.16$ & 0.072 & & & \\
\hline $\begin{array}{l}\text { Histological type (infiltrating ductal carcinoma/ } \\
\text { infiltrating lobular carcinoma/other) }\end{array}$ & 0.86 & $0.65-1.14$ & 0.290 & & & \\
\hline Molecular subtype (basal/HER2/lum. B/lum. A/normal) & 0.99 & $0.82-1.2$ & 0.945 & & & \\
\hline ER (positive/indeterminate/negative) & 0.78 & $0.63-0.97$ & 0.026 & 0.86 & $0.62-1.19$ & 0.351 \\
\hline PR (positive/indeterminate/negative) & 0.78 & $0.64-0.96$ & 0.019 & 0.85 & $0.62-1.15$ & 0.281 \\
\hline HER2 (positive/indeterminate/negative/equivocal) & 0.93 & $0.7-1.22$ & 0.596 & & & \\
\hline Menopause status (post-/peri-/premenopausal/indeterminate) & 0.95 & $0.74-1.22$ & 0.713 & & & \\
\hline Stage $(\mathrm{IV} / \mathrm{III} / \mathrm{II} / \mathrm{I})$ & 1.71 & $1.4-2.08$ & 0.000 & 1.63 & $1.31-2.03$ & 0.000 \\
\hline Lymph node status (yes/no) & 0.86 & $0.7-1.06$ & 0.159 & & & \\
\hline Margin status (positive/close/negative) & 1.59 & $1.23-2.06$ & 0.000 & 1.47 & $1.12-1.92$ & 0.006 \\
\hline LCN1 (high/low) & 1.97 & $1.22-3.18$ & 0.005 & 1.85 & $1.12-3.06$ & 0.016 \\
\hline
\end{tabular}

Bold values $(p<0.05)$ indicate statistically significant correlations. HR, hazard ratio; CI, confidence interval; lum., luminal. 


\section{Discussion}

Our team aimed to determine novel biomarkers for the diagnosis and prognosis of diseases in the field of oncology [15-21]. Analysis of TCGA-BRCA level 3 data demonstrated that LCN1 expression was obviously higher in tumor tissue than in normal tissue. LCN1 expression may be an independent factor for the prognosis of survival in breast cancer patients. Besides, we validated LCN1 expression and survival analyses by GEO datasets. To our knowledge, this is the first study which investigated the association between LCN1 expression and breast cancer.

LCN1, a gene that encodes tear lipocalin, is located on chromosome 9q34 [22]. Tear lipocalin is a member of the lipocalin family and synthesized by 3 genes: LCN1a, LCN1b, and LCN1c. LCN1a encodes tear lipocalin and 2 other genes are not expressed [10]. LCN1 can scavenge lipids from the corneal surface to keep it moist and intact [23]. Compared to control tears, the content of LCN1 was reduced in dry eye disease [24]. LCN1 expression was also decreased in tears of patients with the Sjögren's syndrome [25]. LCN1 expression has also been analyzed in human teratocarcinoma-derived NT2 precursor cells using reverse-transcriptase PCR [26]. However, no other studies have studied its expression levels in malignant tumors, especially breast cancer. In our study, we found that LCN1 expression was obviously higher in tumor than normal tissue based on both the TCGA database and GEO datasets.

LCN1 is a biomarker of many benign diseases, including dry eye disease [27], diabetic retinopathy [28], chronic obstructive pulmonary disease [29], and tobacco-related diseases [30]. However, the role of LCN1 in breast cancer is unclear. In our study, we found that high LCN1 expression was associated with clinicopathologic features, including ER status and menopause. LCN2 has also been reported to affect the steroid status of mammary epithelial cells and change ER status [31]. LCN1 levels were compared in different groups of patients with primary breast tumor, and the results showed that high LCN1 expression was associated with high BMI in breast cancer patients. It is known that obese people are more likely to have hyperlipidemia. LCN1 may be associated with hyperlipidemia, which may be associated with morbidity, tumor growth, and metastases in breast tumors [32]. In addition, high levels of NGAL (neutrophil gelatinase-associated lipocalin), also known as LCN2, in biological fluids may be used to prognosticate disease-free survival in breast cancer patients [33] and were associated with aggressive breast cancer types and a poor prognosis [31]. Our study also indicated that high LCN1 expression was an independent predictor of a poor prognosis in breast cancer patients, and it revealed moderate diagnostic ca- pability in stage IV. LCN1 may be a new biomarker for the diagnosis and prognosis of breast cancer.

LCN1 was reported to bind with a variety of hydrophobic molecules and may act as a scavenger of potentially harmful, hydrophobic molecules $[5,6]$. It was shown to be involved in inflammatory processes of oral and ocular tissue [30], cellular defense against oxidative stress [34], and immune defense against fungal infections [6]. Moreover, LCN1 also participated in the protection of human epithelial cells [35]. LCN2 has been reported as a potential therapeutic target for breast cancer metastases, and abnormal expression of LCN2 was associated with epithelial-to-mesenchymal transition, angiogenesis, cell migration, and invasion in breast cancer [36]. In our study, the results showed that high LCN1 expression was associated with poor survival in patients with infiltrating ductal carcinoma. It is known that invasive ductal carcinoma of the breast originates from the luminal epithelium [37]. High LCN1 expression might have a correlation with infiltrating ductal carcinoma through its effects on mammary epithelial cells. However, experimental confirmation is needed.

Due to the limited number of samples, further analysis of large sample data are required for validation. The results of LCN1 studies in other diseases foster further experiments or clinical studies to verify its significance as a prognostic marker for breast cancer.

In conclusion, we determined the association between LCN1 expression and breast cancer based on TCGA database analyses. Besides, we also validated LCN1 expression and survival analyses by GEO datasets. Thus, LCN1 expression may be an independent predictor of a poor prognosis in breast cancer patients.

\section{Acknowledgments}

The authors would like to acknowledge the use of the public database.

\section{Statement of Ethics}

This study did not require ethical approval as the data used have been published previously, and hence are already in the public domain.

\section{Disclosure Statement}

The authors declare that there are no conflicts of interest.

\section{Funding Sources}

This study was partially supported by a grant for science and technology of the Jilin Province Health and Family Planning Commission Project 2017Q035 (Z.Y.). 


\section{References}

1 Akram M, Iqbal M, Daniyal M, Khan AU. Awareness and current knowledge of breast cancer. Biol Res. 2017 Oct;50(1):33.

2 Wang M, Ji S, Shao G, Zhang J, Zhao K, Wang Z, et al. Effect of exosome biomarkers for diagnosis and prognosis of breast cancer patients. Clin Transl Oncol. 2018 Jul;20(7):90611.

3 Banin Hirata BK, Oda JM, Losi Guembarovski R, Ariza CB, de Oliveira CE, Watanabe MA. Molecular markers for breast cancer: prediction on tumor behavior. Dis Markers. 2014; 2014:513158.

4 Li G, Hu J, Hu G. Biomarker Studies in Early Detection and Prognosis of Breast Cancer. Adv Exp Med Biol. 2017;1026:27-39.

5 Wojnar P, Lechner M, Redl B. Antisense down-regulation of lipocalin-interacting membrane receptor expression inhibits cellular internalization of lipocalin-1 in human NT2 cells. J Biol Chem. 2003 May;278(18): 16209-15.

6 Fluckinger M, Haas H, Merschak P, Glasgow BJ, Redl B. Human tear lipocalin exhibits antimicrobial activity by scavenging microbial siderophores. Antimicrob Agents Chemother. 2004 Sep;48(9):3367-72.

7 Pieragostino D, Agnifili L, Fasanella V, D’Aguanno S, Mastropasqua R, Di Ilio C, et al. Shotgun proteomics reveals specific modulated protein patterns in tears of patients with primary open angle glaucoma naïve to therapy. Mol Biosyst. 2013 Jun;9(6):1108-16.

8 Acera A, Vecino E, Rodríguez-Agirretxe I, Aloria K, Arizmendi JM, Morales C, et al. Changes in tear protein profile in keratoconus disease. Eye (Lond). 2011 Sep;25(9): 1225-33.

9 Tong L, Zhou L, Beuerman RW, Zhao SZ, Li XR. Association of tear proteins with Meibomian gland disease and dry eye symptoms. $\mathrm{Br}$ J Ophthalmol. 2011 Jun;95(6):848-52.

10 Dartt DA. Tear lipocalin: structure and function. Ocul Surf. 2011 Jul;9(3):126-38

11 Wojnar P, Dirnhofer S, Ladurner P, Berger P, Redl B. Human lipocalin-1, a physiological scavenger of lipophilic compounds, is produced by corticotrophs of the pituitary gland. J Histochem Cytochem. 2002 Mar;50(3): 433-5.

12 Karnati R, Laurie DE, Laurie GW. Lacritin and the tear proteome as natural replacement therapy for dry eye. Exp Eye Res. 2013 Dec; 117:39-52.

13 Kim SL, Lee ST, Min IS, Park YR, Lee JH, Kim DG, et al. Lipocalin 2 negatively regulates cell proliferation and epithelial to mesenchymal transition through changing metabolic gene expression in colorectal cancer. Cancer Sci. 2017 Nov; 108(11):2176-86.

14 Yang J, Bielenberg DR, Rodig SJ, Doiron R, Clifton MC, Kung AL, et al. Lipocalin 2 promotes breast cancer progression. Proc Natl Acad Sci USA. 2009 Mar;106(10):3913-8.

15 Jiao Y, Fu Z, Li Y, Meng L, Liu Y. High EIF2B5 mRNA expression and its prognostic significance in liver cancer: a study based on the TCGA and GEO database. Cancer Manag Res. 2018 Nov; 10:6003-14.

16 Jiao Y, Li Y, Lu Z, Liu Y. High Trophinin-Associated Protein Expression Is an Independent Predictor of Poor Survival in Liver Cancer. Dig Dis Sci. 2019 Jan;64(1):137-43.

17 Jiao Y, Fu Z, Li Y, Zhang W, Liu Y. Aberrant FAM64A mRNA expression is an independent predictor of poor survival in pancreatic cancer. PLoS One. 2019 Jan;14(1):e0211291.

18 Jiao Y, Li Y, Liu S, Chen Q, Liu Y. ITGA3 serves as a diagnostic and prognostic biomarker for pancreatic cancer. OncoTargets Ther. 2019 May; 12:4141-52.

19 Jiao Y, Li Y, Jiang P, Han W, Liu Y. PGM5: a novel diagnostic and prognostic biomarker for liver cancer. PeerJ. 2019 Jun;7:e7070.

20 Li Y, Jiao Y, Fu Z, Luo Z, Su J, Li Y. High miR454-3p expression predicts poor prognosis in hepatocellular carcinoma. Cancer Manag Res. 2019 Apr;11:2795-802.

21 Hou L, Zhang X, Jiao Y, Li Y, Zhao Y, Guan $\mathrm{Y}$, et al. ATP binding cassette subfamily B member 9 (ABCB9) is a prognostic indicator of overall survival in ovarian cancer. Medicine (Baltimore). 2019 May;98(19):e15698.

22 Lacazette E, Gachon AM, Pitiot G. A novel human odorant-binding protein gene family resulting from genomic duplicons at 9q34: differential expression in the oral and genital spheres. Hum Mol Genet. 2000 Jan;9(2):289301.

23 Gasymov OK, Abduragimov AR, Prasher P, Yusifov TN, Glasgow BJ. Tear lipocalin: evidence for a scavenging function to remove lipids from the human corneal surface. Invest Ophthalmol Vis Sci. 2005 Oct;46(10):358996.

24 Versura P, Bavelloni A, Grillini M, Fresina M, Campos EC. Diagnostic performance of a tear protein panel in early dry eye. Mol Vis. 2013 Jun;19:1247-57.

25 Versura P, Giannaccare G, Vukatana G, Mulè R, Malavolta N, Campos EC. Predictive role of tear protein expression in the early diagnosis of Sjögren's syndrome. Ann Clin Biochem. 2018 Sep;55(5):561-70.

26 Lechner M, Wojnar P, Redl B. Human tear lipocalin acts as an oxidative-stress-induced scavenger of potentially harmful lipid peroxidation products in a cell culture system. Biochem J. 2001 May;356(Pt 1):129-35.

27 Enríquez-de-Salamanca A, Bonini S, Calonge M. Molecular and cellular biomarkers in dry eye disease and ocular allergy. Curr Opin Allergy Clin Immunol. 2012 Oct;12(5):523-33.

28 Wang JC, Ku HY, Shieh DB, Chuang HS. A bead-based fluorescence immunosensing technique enabled by the integration of Förster resonance energy transfer and optoelectrokinetic concentration. Biomicrofluidics. 2016 Jan;10(1):014113.

29 Nicholas BL, Skipp P, Barton S, Singh D, Bagmane D, Mould R, et al. Identification of lipocalin and apolipoprotein A1 as biomarkers of chronic obstructive pulmonary disease. Am J Respir Crit Care Med. 2010 May;181(10): 1049-60.

30 Jessie K, Pang WW, Haji Z, Rahim A, Hashim $\mathrm{OH}$. Proteomic analysis of whole human saliva detects enhanced expression of interleukin-1 receptor antagonist, thioredoxin and lipocalin-1 in cigarette smokers compared to non-smokers. Int J Mol Sci. 2010 Nov;11(11): 4488-505.

31 Leng X, Wu Y, Arlinghaus RB. Relationships of lipocalin 2 with breast tumorigenesis and metastasis. J Cell Physiol. 2011 Feb;226(2): 309-14.

32 Buss LA, Dachs GU. The Role of Exercise and Hyperlipidaemia in Breast Cancer Progression. Exerc Immunol Rev. 2018;24:10-25.

33 Roli L, Pecoraro V, Trenti T. Can NGAL be employed as prognostic and diagnostic biomarker in human cancers? A systematic review of current evidence. Int J Biol Markers. 2017 Mar;32(1):e53-61.

34 Tam JC, Ko CH, Koon CM, Cheng Z, Lok $\mathrm{WH}$, Lau CP, et al. Identification of Target Genes Involved in Wound Healing Angiogenesis of Endothelial Cells with the Treatment of a Chinese 2-Herb Formula. PLoS One. 2015 Oct;10(10):e0139342.

35 Gutiérrez AM, Montes A, Gutiérrez-Panizo C, Fuentes P, De La Cruz-Sánchez E. Gender influence on the salivary protein profile of finishing pigs. J Proteomics. 2018 Apr;178:10713.

36 Hu C, Yang K, Li M, Huang W, Zhang F, Wang $H$. Lipocalin 2: a potential therapeutic target for breast cancer metastasis. OncoTargets Ther. 2018 Nov; 11:8099-106.

37 Bayram R, Yavuz MZ, Benek BS, Aydogar Bozkurt A, Ucbek A, Ozunal ZG, et al. Effect of Breast Milk Calcium and Fluidity on Breast Cancer Cells: An In Vitro Cell Culture Study. Breastfeed Med. 2016 Nov;11:474-478. 